\title{
Gemcitabine-Induced Acute Coronary Syndrome: A Case Report
}

\author{
Banu Ozturk $^{a}$ Gulten Tacoy $^{\mathrm{b}}$ Ugur Coskun $^{\mathrm{a}}$ Emel Yaman $^{\mathrm{a}}$ Giray Sahin $^{\mathrm{a}}$ \\ Suleyman Buyukberber ${ }^{a}$ Ramazan Yildiz ${ }^{a}$ Ali O. Kaya ${ }^{a}$ Salih Topal ${ }^{b}$ \\ Murat Ozdemir ${ }^{b}$ Mustafa Beneklia \\ Departments of a Medical Oncology and ${ }^{\mathrm{b}}$ Cardiology, Gazi University Medical School, Ankara, Turkey
}

\author{
Key Words \\ Gemcitabine $\cdot$ Coronary syndrome $\cdot$ Left bundle-branch \\ block
}

\begin{abstract}
Objectives: To report a case of metastatic leiomyosarcoma, in which a patient developed chest pain accompanied by acute left bundle-branch block (LBBB) after gemcitabine infusion. Clinical Presentation and Intervention: A 59-yearold woman admitted with bilateral pulmonary nodules had classic risk factors for coronary heart disease and coronary stenosis as demonstrated by previous coronary angiography. She was treated with gemcitabine infusion, and $30 \mathrm{~min}$ later she experienced severe chest pain accompanied by acute LBBB confirmed by ECG. We suspected gemcitabineinduced coronary vasospasm exacerbated by the preexisting coronary artery disease as the cause of the acute coronary syndrome. The patient was subsequently treated with antianginal therapy and percutaneous coronary intervention. Her chest pain resolved and LBBB disappeared. She was discharged 2 days later without any further cardiac events. No additional cancer therapy was given and she died 5 months later, due to disease progression. Conclusion: This case showed that chemotherapeutic agents must be administered with intensive cardiac monitoring especially in patients with cardiac disease and well-known risk factors to prevent the development of cardiac complications, despite an agent not being known to be 'cardiotoxic'.
\end{abstract}

Copyright $\odot 2008$ S. Karger AG, Basel
(C) 2008 S. Karger AG, Basel

1011-7571/09/0181-0076\$26.00/0

Fax +4161306 1234

E-Mail karger@karger.ch

www.karger.com
Accessible online at:

www.karger.com/mpp

\section{Introduction}

Gemcitabine, an analogue of deoxycytidine, exhibits cell phase specificity, primarily killing cells undergoing DNA synthesis (S phase) and also blocking the progression of cells through the G1/S phase boundary. Gemcitabine exhibits clinical activity in a variety of tumors including pancreatic, ovarian, breast, bladder, non-small cell lung cancer and small cell lung cancer $[1,2]$. In metastatic soft tissue and bone sarcomas refractory to standard chemotherapy, gemcitabine was effective in achieving disease stabilization and effected a minimal response in several phase II studies [3]. Gemcitabine is well tolerated by patients; myelosuppression (especially thrombocytopenia) is its doselimiting side effect. Other side effects including nausea, vomiting, rash, fever, and alopecia are mild or moderate. Drug-induced pulmonary toxicity is a rare but important complication of gemcitabine administration [4]. The elevation of serum transaminases, hematuria, proteinuria are rare and not severe. The most common cardiotoxic effect due to antimetabolites is coronary ischemia [5]. There are only a few case reports of cardiovascular adverse effects associated with gemcitabine in the literature.

\section{Case Report}

A 59-year-old woman was admitted to hospital for bilateral pulmonary nodules. Fluorine-18-deoxy-fluoro-D-glucose $\left({ }^{18} \mathrm{~F}\right.$ FDG) PET-CT scanning revealed ${ }^{18} \mathrm{~F}$-FDG uptake in pulmonary

Ugur Coskun, MD

Associate Professor of Oncology

Department of Medical Oncology, Gazi University Medical School

TR-06500 Besevler, Ankara (Turkey)

Tel. +90 312202 4197, Fax +90 312215 8710, E-Mail drbanutr@yahoo.com 


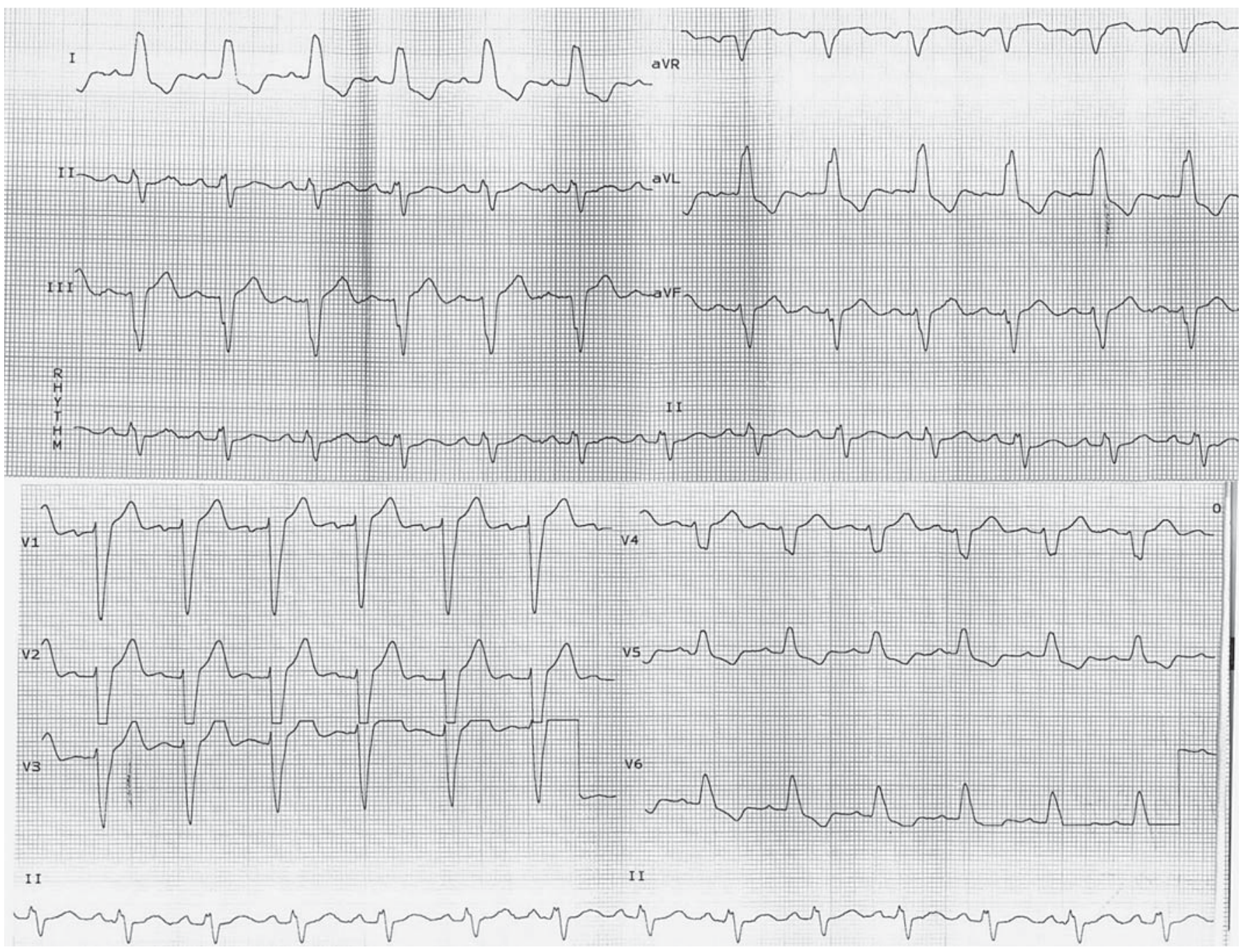

Fig. 1. ECG after gemcitabine infusion showed LBBB.

nodules. Before diagnostic procedures for these nodules, she had mild to moderate chest pain. A coronary angiography was performed and revealed $80 \%$ stenosis in the bifurcation of the left anterior descending artery and the first diagonal branch. She had hypertension, diabetes mellitus, a family history of coronary artery disease, and hyperlipidemia. Medical treatment with aspirin, beta-blocker and nitrate was initiated. After cardiac stabilization, fine-needle aspiration biopsy was performed from the pulmonary nodules and metastatic leiomyosarcoma was diagnosed. She was asymptomatic and refused anticancer therapy. A mass on her right shoulder and another on her scalp developed 1 year later; both were excised and pathological findings were consistent with leiomyosarcoma. Multiple pulmonary metastases and a mass about $5 \mathrm{~cm}$ in diameter near the liver and diaphragm were detected in chest and abdominal CT scans. She received two courses of ifosfamide, but the abdominal mass progressed and a new chemotherapy regimen consisting of docetaxel and gemcitabine was begun. She received $900 \mathrm{mg} / \mathrm{m}^{2}$ gemcitabine i.v. over $90 \mathrm{~min}$ on days 1 and $8,100 \mathrm{mg} / \mathrm{m}^{2}$ docetaxel i.v. over $1 \mathrm{~h}$ on day 8 . Three days after administration of docetaxel and gemcitabine and on the 8 th day of therapy, she experienced mild chest pain, which resolved spontaneously. She was admitted to the hospital for a second cycle of chemotherapy and hospitalized for close monitoring. After $30 \mathrm{~min}$ of gemcitabine infusion, she experienced severe chest pain accompanied by acute left bundle-branch block (LBBB, fig. 1). She was transferred to the coronary care unit where she received anticoagulant and antithrombotic therapy consisting of aspirin, clopidogrel, a heparin infusion, and beta-blocker nitrate treatment. Within 10 min of admission to the coronary care unit, her chest pain resolved and LBBB disappeared (fig. 2). Her physical examination was normal; she had an ejection fraction of 0.60 on echocardiogram. Her laboratory findings were in the normal range. Levels of troponin $\mathrm{T}$, creatinine kinase and $\mathrm{MB}$ fractions were within normal limits at 6 and $12 \mathrm{~h}$. A selective coronary angiography showed $80 \%$ stenosis in the bifurcation of the left anterior descending artery and the first diagonal branch, which was 

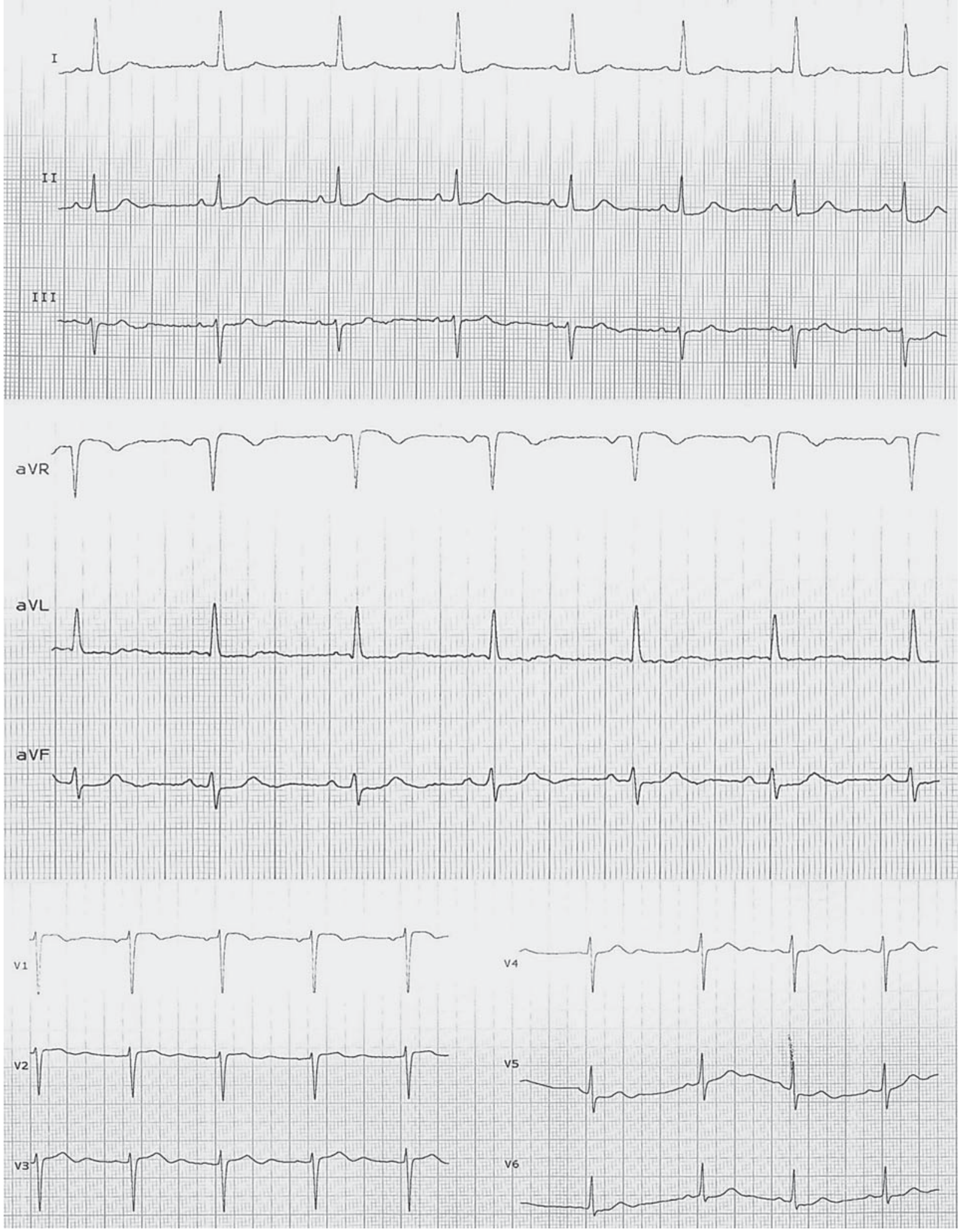

Fig. 2. ECG after anticoagulant and antithrombotic therapy; LBBB disappeared. 
successfully treated with percutaneous coronary intervention. She was discharged after 2 days without any adverse cardiac events with antiaggregant (aspirin, clopidogrel), beta-blocker nitrate treatment. No additional anticancer therapy was given and she died 5 months later due to disease progression.

\section{Discussion}

Cardiotoxicity is a significant complication of chemotherapy. Cardiac events may include mild blood pressure changes, thrombosis, electrocardiographic changes, arrhythmias, myocarditis, pericarditis, myocardial infarction, cardiomyopathy, cardiac failure (left ventricular failure) and congestive heart failure $[5,6]$. These may occur during or shortly after treatment, within days or weeks after treatment, or may not be apparent until months, and sometimes years after the completion of chemotherapy [5, 6]. Factors attributable to the drug (such as type of drug, cumulative or total dose and schedule) and patient characteristics including age, prior chest-mediastinal irradiation history, concurrent administration of cardiotoxic agents, electrolyte imbalances such as hypokalemia and hypomagnesemia, history of cardiac diseases and other risk factors of atherosclerosis influence the incidence and severity of chemotherapy-induced adverse cardiac reactions $[5,6]$. Our case concerned a woman with a history of coronary artery disease who developed acute coronary syndrome after chemotherapy although already receiving antithrombotic, beta-blocker and nitrate therapy.

Anthracycline-induced cardiomyopathy is the most well-known cardiac event [6]. Alkylating agents such as cyclophosphamide, ifosfamide, cisplatin and other agents including paclitaxel, etoposide, teniposide, the Vinca alkaloids, fluorouracil are known to cause several adverse cardiac effects $[5,6]$. Fluoropyrimidines can cause angina such as chest pain, myocardial infarction and sudden cardiac death. 5-Fluorouracil (5-FU) belongs to the group of pyrimidine analogues, and although cardiac toxicity occurs in $1-3 \%$ of patients, the incidence of acute coronary syndrome during 5-FU treatment is very low [7]. Underlying mechanisms of cardiac ischemia are still unknown. The most likely mechanism is coronary vasospasm. Transient coronary vasospasm may cause stable or unstable angina pectoris, whereas persistent vasospasm may result in acute myocardial infarction (AMI). Canale et al. [8] reported a subject developing AMI during 5-FU infusion who did not have classic risk factors for coronary heart disease and no evidence of coronary stenosis on coronary angiography. This finding is supported by the probability of coronary spasm due to 5-FU infusion. Capecitabine, an oral fluoropyrimidine, is a prodrug that metabolizes to 5-FU. Several case reports demonstrated acute coronary syndrome related to capecitabine treatment; similarly 5-FU coronary vasospasm was the most likely reason of this acute adverse cardiac event [9].

Gemcitabine-induced acute coronary syndromes are rarely described in the literature. Bdair et al. [10] reported a case with previous myocardial infarction history, which developed AMI 3 days after gemcitabine therapy. Our subject, who had a history of coronary artery disease, developed chest pain with accompanying newly developed LBBB shortly after drug infusion, but no biomarker increases were observed and both symptoms and LBBB resolved with antianginal treatment. We speculate that gemcitabine-induced coronary vasospasm combined with preexisting coronary artery disease was the cause of the acute coronary syndrome, which subsequently was treated by antianginal therapy and percutaneous coronary intervention. Dumontet et al. [11] reported a case with gemcitabineinduced AMI in which previous cardiac disease was known and AMI occurred 4 days after infusion of gemcitabine. In contrast to previous reports, in our case, acute coronary syndrome developed during the treatment. Similarly, in a case report by Kalapura et al. [12], a coronary event was documented $6 \mathrm{~h}$ after the fifth cycle of gemcitabine; interestingly there was no cardiac history in this case.

The mechanism of gemcitabine-induced coronary ischemia is still unclear. Similar to 5-FU, coronary spasm is possible. Endothelial dysfunction and coronary thrombosis are other potential explanations. Physicians should take the rare but severe complication of gemcitabine treatment into consideration as intensive cardiac monitoring is essential to prevent the development of fatal cardiac complications, including AMI and severe arrhythmias, particularly in patients with cardiac disease and well-known risk factors. For these patients, a detailed cardiac examination must be performed and antithrombotic and nitrate prophylaxis should be initiated before chemotherapy regardless of whether or not the cytotoxic agent is known to be cardiotoxic.

\section{Conclusion}

This case showed that chemotherapeutic agents must be administered with intensive cardiac monitoring especially in patients with cardiac disease and well-known risk factors to prevent the development of cardiac complications, despite an agent not being known to be 'cardiotoxic'. 


\section{References}

-1 Carmichael J, Fink U, Russell RC, Spittle MF, Harris AL, Spiessi G, Blatter J: Phase II study of gemcitabine in patients with advanced pancreatic cancer. Br J Cancer 1996;73:101105.

-2 Abbratt RP, Bezwoda WR, Falkson G, Goedhals L, Hacking D, Rugg TA: Efficacy and safety profile of gemcitabine in non-smallcell lung cancer: a phase II study. J Clin Oncol 1994;12:1535-1540.

$\checkmark 3$ Hartmann JT, Oechsle K, Huober J, Jakob A, Azemar M, Horger M, Kanz L, Bokemeyer C: An open label, non-comparative phase II study of gemcitabine as salvage treatment for patients with pretreated adult type soft tissue sarcoma. Invest New Drugs 2006;24:249253.

4 Coskun U, Günel N, Yildirim Y: Gemcitabine induced pulmonary injury. Case Rep Pract Rev 2004;5:178-179.
5 Yeh ET, Tong AT, Lenihan DJ, Yusuf SW, Swafford J, Champion C, Durand JB, Gibbs $\mathrm{H}$, Zafarmand AA, Ewer MS: Cardiovascular complications of cancer therapy: diagnosis, pathogenesis, and management. Circulation 2004;109:3122-3131.

6 Pai VB, Nahata MC: Cardiotoxicity of chemotherapeutic agents: incidence, treatment and prevention. Drug Saf 2000;22:263-302.

7 Labianca R, Beretta G, Clerici M, Frascini P, Luporini G: Cardiac toxicity of 5-fluorouracil: a study of 1083 patients. Tumori 1982;68: 505-510.

$\checkmark 8$ Canale ML, Camerini A, Stroppa S, Porta RP, Caravelli P, Mariani M, Balbarini A, Ricci S: A case of acute myocardial infarction during 5-fluorouracil infusion. J Cardiovasc Med (Hagerstown) 2006;7:835-837.
9 Wijesingle N, Thompson PI, McAlister H: Acute coronary syndrome induced by capecitabine therapy. Heart Lung Circ 2006; 15:337-339.

10 Bdair FM, Graham SP, Smith PF, Javle MM: Gemcitabine and acute myocardial infarction: a case report. Angiology 2006;57:367371.

11 Dumontet C, Morschhauser F, Solal-Celigny P, Bouafia F, Bourgeois E, Thieblemont C, Leleu X, Hequet O, Salles G, Coiffier B: Gemcitabine as a single agent in the treatment of relapsed or refractory low-grade non-Hodgkin's lymphoma. Br J Haematol 2001;113: 772-778.

12 Kalapura T, Krishnamurthy M, Reddy CV: Acute myocardial infarction following gemcitabine therapy: a case report. Angiology 1999;50:1021-1025.

\section{Announcement}

14th Health Sciences Center Poster Conference 2009

Faculty of Medicine, Kuwait University, Kuwait, April 21-23, 2009

\section{Announcement and Call for Abstracts}

Sponsor: Faculty of Medicine, Kuwait University, Kuwait

Venue: Health Sciences Center, Kuwait University, Kuwait

Deadline for submission of abstracts: January 29, 2009

Abstracts must be submitted online: www.hsc.edu.kw/poster2009 or by E-Mail: poster2009@hsc.edu.kw

Keynote speaker: Prof. R. Brian Haynes, Clinical Epidemiology and Medicine, Health Information Research Unit, Faculty of Health Science, McMaster University, Hamilton, Ontario, Canada

Title: Evidence-Based Medicine and Knowledge Translation Research for Better Health Care

Deadline for registration: Onsite

\section{Poster Awards}

A chance to win:

- Dr. Nael Al-Naqeeb Award (for undergraduate students)

- Graduate Award (Basic Sciences)

- Graduate Award (Residents)

- Basic Sciences Award

- Clinical Sciences Award

For further information, contact:

Teena Sadan, Conference Secretary: Tel. +965 249 86418, E-Mail: teena@hsc.edu.kw 